\title{
sit \\ Heisenberg e a doutrina das cores de Goethe e Newton
}

\author{
Alexandre de Oliveira Ferreira
}

Este artigo destina-se a introduzir a conferência de Heisenberg "A doutrina goethiana e newtoniana das cores à luz da física moderna”, proferida em 1941, cuja tradução é aqui publicada. Analisa-se primeiramente o projeto filosófico de uma ordenação da realidade, desenvolvido pelo físico no início da década de 194,0, o qual subjaz à discussão sobre as doutrinas das cores em Goethe e Newton. No segundo momento, faz-se uma exposição de algumas das implicações filosóficas da teoria quântica, com ênfase na interpretação da assim denominada escola de Copenhague. Por fim, procura-se mostrar como a querela entre Goethe e Newton é utilizada para defender as abstrações da física teórica dos ataques da assim denominada "física ariana" e, ao mesmo tempo, preservar o valor das considerações intuitivas de Goethe.

\footnotetext{
$* * *$

O oposto de uma suposição correta é uma suposição falsa. Mas o oposto de uma verdade profunda pode também ser uma verdade profunda (Niels Bohr apud Heisenberg, 2005a, p. 124).
}

\section{INTRODUÇÃO}

A conferência, cuja tradução é aqui publicada, faz parte de uma reunião de palestras proferidas por Heisenberg entre 1933 e 1958, intitulada Mudanças nos fundamentos das ciências da natureza (cf. Heisenberg, 2005b). Essa coletânea insere-se em um conjunto mais amplo de textos e comunicações que o físico produziu durante toda sua vida e que têm como objetivo a redução daquilo que denomina de "abismo entre duas culturas, entre a cultura técnico-científica e a cultura das ciências humanas e da arte" (Heisenberg, 2005a, p. 7). 
Assim, devemos cuidar para não interpretar "A doutrina goethiana e newtoniana das cores à luz da física moderna" como uma tentativa de informar o leitor leigo das descobertas da física quântica a fim de que a nova física pudesse iluminar e esclarecer as doutrinas das cores de Goethe e Newton mediante uma explicação mais "verdadeira”. A discussão entre o físico inglês e o poeta, várias vezes retomada por Heisenberg, remete antes a um projeto filosófico desenvolvido pelo físico alemão no início da década de 1940 cujo objetivo é identificar uma ordem e uma unidade entre os diversos modos do saber humano. Segundo esse projeto, ciência e arte não podem ser reduzidas uma à outra ou explicadas uma pela outra, mas devem antes ser pensadas como domínios ou modos diferentes de ordenação da realidade, cuja relação deve ser redefinida com o advento da teoria quântica.

Com efeito, o desenvolvimento da física quântica, no início do século xx, faz com que a batalha entre Goethe e Newton já não possa ser decidida dentro do referencial teórico da física clássica que opõe o discurso objetivo e exato da ciência à linguagem subjetiva e alegórica do poeta. Segundo a interpretação da "escola de Copenhague”, com a teoria quântica não apenas é descartada a possibilidade de se descrever uma realidade independente do observador, como o próprio alcance dos conceitos clássicos torna-se problemático. Nas palavras de Niels Bohr, conceitos clássicos como "partícula" e "onda", quando aplicados a fenômenos quânticos, são meras metáforas que visam expressar, à maneira dos poetas, um estado de coisas que foge à nossa intuição (cf. Heisenberg, 2005a, p. 54).

Em um segundo momento, a disputa entre Goethe e Newton é utilizada para discutir o próprio valor das ciências naturais que, de modo sempre crescente, substituem nossa experiência viva e intuitiva do mundo por uma natureza tecnicamente produzida, explicada mediante abstrações que não podem ser diretamente traduzidas em conceitos intuitivos. Essa defesa da física teórica se deve, em grande parte, à necessidade de responder às objeções da assim denominada física alemã (deutsche Physik), ou física ariana (arische Physik). Iniciado na primeira metade da década de 1920, esse movimento ganhou proeminência com a ascensão do nazismo, sustentando que as ciências são determinadas por elementos culturais e raciais. Os autodenominados fisicos arianos, dentre eles os ganhadores do prêmio Nobel, Philipp Lenard e Johannes Stark, rotulam a física quântica e a teoria da relatividade como físicas judaicas, calcadas em

1 A assim denominada "escola de Copenhague" representa uma determinada interpretação da teoria quântica que começa a se consolidar a partir da segunda metade dos anos vinte, sustentada por físicos e pesquisadores ligados a Bohr, dentre eles Heisenberg e Pauli. Portanto, as conclusões da escola de Copenhague não são uma unanimidade entre os físicos, existindo outras interpretações divergentes. Entretanto, para os nossos propósitos, iremos nos concentrar apenas nela. Cf., para uma consideração mais detida do desenvolvimento da teoria quântica, Bezerra, 2003, 2004). 
meras abstrações e especulações que não possuem respaldo na experiência. Em contraposição aos defensores da deutsche Physik, para os quais Goethe era considerado um modelo a ser seguido, Heisenberg cria um pano de fundo filosófico que permite ordenar em um todo coerente a objetividade da física clássica, as abstrações da teoria quântica e as intuições poéticas de Goethe.

\section{GoETHE E A ORDENAÇÃo DA REALIDADE}

A busca por uma unidade do saber humano é um tema recorrente entre os cientistas com os quais Heisenberg dialoga. Planck, Einstein, Bohr, dentre outros grandes nomes da física do século xx, escreveram textos sobre a relação entre a física e as outras áreas do conhecimento e sobre as implicações epistemológicas das descobertas científicas. Como observa Helmut Rechenberg, Heisenberg considera como um dos aspectos mais importantes da obra de Bohr, ao lado dos seus estudos sobre física, o esforço na "criação de um meio espiritual no interior do qual as diversas linhas da moderna ciência da natureza se unificassem e pudessem ser postas em relação com o fundo filosófico comum a todas as ciências" (Heisenberg apud Blum; Dürr \& Rechenberg, 1986, p. 411).

Destarte, à época da preleção sobre a doutrina das cores de Goethe e Newton, Heisenberg trabalhava em um projeto filosófico que buscava pensar a unidade entre as ciências da natureza e as ciências do espírito a partir da ideia de que os diversos modos do saber humano constituem determinados domínios (Bereiche) da realidade. Isso resultou na elaboração de um manuscrito concluído em 19422 e publicado postumamente sob o título "Ordenação da realidade". Heisenberg toma como modelo para tal ordenação uma passagem de um suplemento à Doutrina das cores de Goethe, na qual o poeta diz:

Todos os efeitos, de quaisquer tipos que sejam, que observamos na experiência estão conectados da maneira mais constante possível, convertem-se uns nos outros, ondulam do primeiro até o último. É inevitável que se os separem uns dos outros, que se os oponham e que se os misturem; todavia precisou surgir com isso uma contenda sem limites nas ciências. Uma pedanteria que cinde de maneira inflexível e um misticismo fluidificante produzem ambos as mesmas desgraças. Mas aquelas atividades, da mais comum até a mais elevada, da telha que cai do telhado até o olhar luminoso do espírito que irrompe em ti ou que tu medeias, se encontram justapostas. Nós tentamos expor esse fato: casual; mecânico; físico; químico; orgânico; psíquico; ético; religioso; genial (Goethe apud Heisenberg, 2009, p. 27-8). 
Essa passagem, citada por Heisenberg em várias ocasiões, denota o respeito que possuía não apenas pela poesia de Goethe, como também por seus estudos sobre a natureza. Admirador do poeta desde a juventude, a ponto de saber de cor vários dos seus escritos, o físico acredita que todo grande cientista da natureza possuía uma afinidade com a poesia. Entretanto, para compreendermos como é possível que Heisenberg possa inspirar-se em um modelo de ordenação proposto por um dos maiores inimigos da física newtoniana, faz-se necessária uma breve análise da interpretação que ele faz dessa divisão da realidade sugerida por Goethe.

Segundo Heisenberg, não se trata aqui de uma divisão entre as coisas que existem na natureza, como se a pedra estivesse no nível mais baixo e o espírito humano no mais elevado. Quando Goethe se refere a cada uma dessas regiões como "atividades" (Tätigkeiten), ele estaria antes indicando que o que determina um domínio e o separa dos outros são as leis ou normas (Gesetze) que possibilitam o estabelecimento de determinados nexos (Zusammenhängen) na natureza. A ideia de lei é tomada em um sentido amplo, aproximando-se do nomos grego, indicando que tanto as leis "naturais" quanto as normas que nos orientam no mundo são dependentes dos nexos que estabelecemos entre as coisas. Desse modo, Heisenberg define a realidade como uma tessitura (Gewebe) composta por nexos nomológicos (gesetzmässige Zusammenhänge). Cada unidade nomológica é um domínio da realidade, tomada como uma totalidade (Gesamtheit) dotada de sentido. Com isso, a tarefa filosófica proposta pelo físico seria a de:

Compreender e determinar em sua relação recíproca os diversos nexos ou "domínios da realidade"; colocá-los em ligação com a divisão em um mundo "objetivo" e um "subjetivo"; delimitá-los reciprocamente e perceber como eles são condicionados uns pelos outros; por fim, avançar até uma compreensão da realidade como parte de um único mundo ordenado e dotado de sentido (Heisenberg, 2009, p. 9).

O uso de aspas na citação acima se deve ao fato de o conceito de realidade aqui proposto não admitir uma divisão estanque entre um mundo objetivo e um mundo subjetivo. A ideia de uma objetividade totalmente independente do nosso modo de pensar e agir está totalmente descartada da definição de realidade defendida por Heisenberg. Para aqueles que sustentam que há uma realidade "em si", o físico nos diz que "a expressão 'há' provém da linguagem humana e, com isso, não pode significar bem algo que não estaria de maneira alguma ligado à nossa capacidade cognitiva. Para nós só há justamente o mundo no qual a expressão 'há' tem sentido" (Heisenberg, 2009, p. 34). Assim, os nexos de sentido das diferentes camadas (Schichten) da realidade devem ser sempre expressos pela linguagem, essa última tomada em sentido bastante 
amplo, envolvendo tanto a linguagem cotidiana, quanto a poesia e a matemática. Heisenberg relaciona o grau de objetividade de um domínio da realidade a dois modos distintos, porém inseparáveis, de expressão, a saber, o estático e o dinâmico.

No modo estático a linguagem é usada do ponto de vista da exatidão. Isso exige uma acuidade e especialização no uso dos conceitos, a fim de que eles possam reproduzir com precisão um determinado estado de coisas. Esse rigor conceitual supõe um rígido formalismo no encadeamento dos conceitos, de modo que cada sentença possa ser inequivocamente caracterizada como verdadeira ou falsa. $\mathrm{O}$ modo estático prevalece, por exemplo, na linguagem do direito, da ciência e da matemática. Entretanto, a rígida especialização e a acuidade no uso dos conceitos trazem consigo uma limitação e empobrecimento da linguagem, a qual só pode ser usada em relação a um domínio específico da realidade, renunciando a uma multiplicidade de possibilidades e relações.

No modo dinâmico, o que está em jogo não é a exatidão, mas a criatividade. A linguagem dinâmica é prolífera e flexível, ela não procura esclarecer (erklären) um estado de coisas com precisão, mas antes indicar (deuten) uma gama de possíveis relações. Nela as frases não são corretas (richtig) ou falsas (falsch), mas verdadeiras (wahr). “O contrário de uma proposição 'correta' é uma proposição 'falsa'. O contrário de uma proposição verdadeira, porém, será com frequência também uma proposição verdadeira" (Heisenberg, 2009, p. 15). Exemplos do uso dinâmico da linguagem são a religião, o mito e a poesia.

Como foi dito, todo modo de expressão da realidade é ao mesmo tempo estático e dinâmico. Um pensamento unicamente estático cairia em um formalismo estéril e o excesso de dinamismo levaria a relações vagas e ininteligíveis. Aqui se faz ver o apreço que Heisenberg tem pela poesia como modo de expressão no qual esses dois extremos se encontram, pois ela une a palavra viva e dinâmica a um formalismo, em um certo sentido matemático, expresso no ritmo e na métrica. Mais ainda, para Heisenberg a passagem de um domínio já conhecido para um novo não pode ocorrer mediante mero uso lógico da linguagem (aqui vê-se claramente uma crítica ao positivismo lógico), mas apenas mediante um pensamento criativo que possa saltar (überspringen) o abismo entre eles.

O surgimento de um novo domínio da realidade, inaugurado pela mecânica quântica, exige uma reordenação do mundo, pois "sempre que um novo conhecimento fundamental aparece à consciência dos homens, em uma determinada situação da vida espiritual, a questão sobre aquilo que é afinal propriamente a realidade precisa ser novamente colocada à prova e respondida" (Heisenberg, 2009, p. 3).

A seguir, mostraremos alguns aspectos da teoria quântica que rompem com a objetividade inaugurada pela física clássica, exigindo um novo modo de ordenação da realidade. Concentraremo-nos em uma determinada interpretação da física quântica à qual Heisenberg se vincula, a saber, a assim denominada escola de Copenhague. 


\section{O SIGNIFIGADO DA PALAVRA “ENTENDER” NA FÍSIGA MODERNA}

Um bom começo para compreendermos as implicações filosóficas da teoria quântica é nos remetermos a uma questão de cunho epistemológico, que preocupava Heisenberg desde os seus primeiros anos como estudante de física, concernente ao significado da palavra "entender" (Verstehen) nas ciências da natureza. A esse respeito, ele nos lembra de uma conversa ocorrida no ano de 1921 (cf. Heisenberg, 2005a, p. 39-56), durante um passeio de bicicleta com seu então colega do quarto semestre do curso de física na Universidade de Munique e futuro ganhador do prêmio Nobel em 1945, Wolfgang Pauli. Ambos eram alunos de Arnold Sommerfeld, ${ }^{2}$ em cujos seminários eram estudados o modelo atômico do físico dinamarquês Niels Bohr e a teoria da relatividade especial de Albert Einstein. Também tomou parte nesse passeio o jovem estudante Otto Laporte, cujo "pragmatismo sóbrio e sensato", segundo Heisenberg, servia de contraponto à índole filosófica dos outros dois interlocutores.

A importância dessa conversa, ocorrida quando o físico tinha apenas vinte anos de idade, é assinalada por Heisenberg em várias de suas comunicações direcionadas ao público não especializado. O físico relembra esse diálogo até mesmo em conversas posteriores com Pauli (cf. Heisenberg, 2005a, p. 241-55), quando ambos já possuíam grande renome como ganhadores do prêmio Nobel.

No diálogo em questão, Heisenberg confessa a seus colegas que as discussões sobre a teoria da relatividade, ocorridas durante os seminários de Sommerfeld, levaram-no a questionar o significado da palavra "entender" nas ciências da natureza. Isso porque não conseguia conceber intuitivamente a nova concepção de tempo introduzida por Einstein, embora compreendesse o arcabouço matemático de sua teoria. E acrescenta:

Mas me sinto de certa forma enganado pela lógica com a qual esse arcabouço matemático trabalha. Ou você também pode dizer que eu compreendi a teoria com a cabeça, mas não com o coração. Eu acredito compreender o que significa "tempo", mesmo sem ter estudado física, e nosso pensar e agir pressupõem sempre esse conceito ingênuo de tempo. Talvez se possa também formular isso assim: nosso pensamento se apoia no fato de que esse conceito de tempo funciona, de que obtemos êxito com ele. Mas se agora afirmamos que esse conceito de tempo deve ser modificado, então já não sabemos se nossa linguagem e nosso pensa-

2 Arnold Johannes Wilhelm Sommerfeld (1868-1951), indicado várias vezes ao prêmio Nobel de física, sem nunca ter ganho, foi professor e orientador de Heisenberg e Pauli. Contribuiu no aperfeiçoamento do modelo atômico de Bohr e foi fundamental no desenvolvimento da teoria quântica. 
mento são ferramentas úteis para nos orientarmos. Com isso não pretendo me reportar a Kant, que caracteriza o espaço e o tempo como formas a priori da intuição e com isso deseja conceder um título absoluto a essas formas fundamentais, assim como elas parecem valer na física anterior. Apenas quero frisar que, quando alteramos esses conceitos fundamentais, nossa linguagem e pensamento tornam-se incertos, e incerteza não se coaduna com entendimento (Heisenberg, 2005 a, p. 41-2).

A dúvida de Heisenberg diz respeito a um dos problemas fundamentais no processo de constituição da física moderna, ${ }^{3}$ a saber: até que ponto nossa linguagem, formada por conceitos que, em certa medida, apoiam-se em nossa experiência intuitiva da natureza, pode servir a uma ciência cujos "objetos" escapam à nossa intuição imediata das coisas.

É bem verdade, como reconhece Heisenberg, que na passagem da física antiga para a física clássica houve também a necessidade de se introduzir novos conceitos, de caráter matemático e abstrato, que subvertiam noções da física aristotélica e ptolomaica, mais próximas à nossa intuição imediata da natureza. Nesse sentido, Copérnico e Galileu teriam provocado uma revolução no mundo antigo muito mais profunda que a da física moderna no mundo clássico. Os fundadores da física clássica teriam introduzido noções totalmente alheias às concepções antigas da natureza, ao passo que a física moderna fora desenvolvida na tentativa de realizar de modo coerente o programa da física clássica (cf. Heisenberg, 2005b, p. 33). Embora rompendo com a teoria clássica, a física moderna expressaria uma tendência (crescente nas ciências da natureza desde, pelo menos, a revolução científica do século xVII) de se distanciar de uma apreensão intuitiva do mundo em direção a um domínio cada vez mais abstrato do saber e a uma experiência da natureza forjada mediante meios técnicos sempre mais sofisticados.

Entretanto, como observa Michel Paty, apesar de os conceitos da física clássica serem entidades abstratas e matematizadas, eles "possuíam a faculdade de ser, em seguida, rapidamente investidos com todas as aparências do "natural", em uma física adaptada à experiência familiar do mundo sensível” (Paty, 1995, p. 139). Assim, a física clássica trata do deslocamento dos corpos no espaço e de suas modificações no tempo, segundo leis causais regulares e constantes. Sua objetividade é conduzida pela certeza de um mundo objetivo e mecânico, no qual espaço e tempo, entidades consideradas inalteráveis e independentes entre si, configuram o esquema universal de todo acon-

3 É importante ter claro que a expressão "física moderna" indica a física que surge no século xx, em contraposição à "física clássica" que tem início na idade moderna. Em termos históricos, podemos dizer que a física clássica se refere à idade moderna e a física moderna à nossa contemporaneidade. 
tecimento possível e apresentam uma realidade independente de qualquer observador e comum a todos os homens (cf. Heisenberg, 2005b, p. 32). Não é por acaso que Kant faz do espaço e do tempo as formas puras da intuição sensível, as quais, unidas às categorias do entendimento (dentre elas a causalidade), constituem a condição de possibilidade de todo objeto da experiência. Embora, para Kant, essas condições a priori sejam dadas no sujeito, sua validade é objetiva e seu alcance universal, traçando os limites de todo conhecimento teórico humano dentro dos quais foram elaborados os conceitos da física clássica. É justamente o caráter absoluto dessas formas e categorias e, consequentemente, da própria objetividade do mundo, que começa a ser abalado pela teoria da relatividade e, de modo mais radical, pela mecânica quântica.

Por exemplo, as teorias da relatividade especial e geral destroem a concepção do senso comum de que tempo e espaço são entidades independentes e inalteráveis. Dito de modo sumário, a teoria da relatividade especial demonstra, dentre outras coisas, que tempo e espaço variam relativamente ao lugar e à velocidade do observador. A teoria da relatividade geral mostra como a gravidade e, consequentemente, a matéria e a energia atuam no espaço-tempo e o deformam. Espaço e tempo já não são formas independentes e imutáveis nas quais os eventos ocorrem, mas variam em função do movimento e da matéria.

Porém, apesar de subverter nossas experiências cotidianas do espaço e do tempo, a teoria da relatividade parece ainda poder ser intuída mediante experimentos facilmente imagináveis(cf. Paty, 1995, p. 140). Talvez tenha sido essa possibilidade de tradução das noções introduzidas pela teoria da relatividade para nossa intuição que levou o pragmático Otto Lapport, no diálogo em questão, a tomar por infundadas as dúvidas de Heisenberg com respeito ao uso da nossa linguagem na descrição de fenômenos físicos que parecem subverter nossa intuição do tempo e do espaço. Bastaria restringir a linguagem àquilo que é imediatamente dado à observação sensível, mesmo que essa observação seja feita através de aparatos técnicos complexos, para que saibamos exatamente a qual objeto cada conceito se refere. Laporte acreditava que a teoria da relatividade especial teria como ponto de partida o conceito banal de tempo, a saber, o tempo que observamos no relógio. Para ele, Einstein teria se inspirado no método positivista do físico e filósofo Ernst Mach, ${ }^{4}$ segundo o qual os conceitos da física devem obedecer a uma economia do pensamento. Ou seja, "entender" não significaria nada além do que capturar uma multiplicidade de fenômenos dados na observação sensível em um número reduzido e simplificado de conceitos e formulações matemáticas

4. A obra de Mach a qual Laporte se refere e na qual é exposto o principio de economia do pensamento é Die Mechanik in ihrer Entwicklung historischkritisch Dargestellt (A mecânica em seu desenvolvimento exposta de modo histórico-crítico), publicada em 1883 (cf. Paty, 1995, p. 45). Posteriormente, em suas "Notas autobiográficas", publicadas em 1949, Einstein afirma ter sofrido grande influência dessa obra (cf. Einstein, 1982, p. 29). 
para, desse modo, poder prever uma série de acontecimentos. Nesse sentido, a diferença entre a astronomia de Ptolomeu e a de Newton seria apenas relativa ao grau de previsibilidade do movimento dos corpos celestes. A mecânica newtoniana estaria baseada em conceitos cuja representação matemática seria mais simples e precisa na previsão dos fenômenos do que os ciclos e epiciclos do sistema ptolomaico.

Esse positivismo ingênuo, que Laporte acreditava estar na base da teoria da relatividade especial, foi desmentido pelo próprio Einstein em uma conversa com Heisenberg no ano de 1926, após um colóquio sobre física moderna na Universidade de Berlin. Na ocasião, o pai da teoria da relatividade admitia não compreender como seria possível que Heisenberg afirmasse a existência dos elétrons no átomo e, ao mesmo tempo, negasse a possibilidade de descrever sua trajetória ao redor do núcleo. Heisenberg responde dizendo que, como não se pode observar diretamente a trajetória de um elétron, apenas frequências da luz emitida por ele quando perde energia, nada se poderia afirmar sobre a existência ou não de sua órbita ao redor do núcleo. Com isso, acreditava adotar um método semelhante ao que o próprio Einstein, inspirado em Mach, utilizara na elaboração da teoria da relatividade, a saber: uma teoria deveria ser elaborada apenas a partir de grandezas que pudessem ser empiricamente observáveis e cujas leis pudessem ser descritas do modo mais econômico possível.

Segundo o relato de Heisenberg, Einstein respondera a essas observações dizendo existir certa confusão em relação à influência de Mach na elaboração da teoria da relatividade. Mais ainda, segundo ele: "do ponto de vista do princípio, é totalmente falso querer fundamentar uma teoria apenas sobre grandezas observáveis. Apenas a teoria decide sobre o que pode ser observado" (Heisenberg, 2005a, p. 80). Einstein acredita que a simplicidade das leis pelas quais descrevemos a experiência não pode ser apenas um modo de calcular e prever determinados eventos, ela tem de ser antes a expressão real da maneira pela qual a natureza efetivamente se comporta, devendo revelar um nexo na natureza que subjaz à multiplicidade das experiências sensíveis e que independe de qualquer observador. Apenas quando possuímos uma teoria podemos identificar vários fenômenos como conectados entre si e, assim, podemos observá-los de fato. Einstein adota certo realismo 5 segundo o qual as fórmulas matemáticas e os conceitos pelos quais prevemos os acontecimentos naturais constituem uma parte importante da natureza: "O possível, o que é esperado, é um componente importante de nossa realidade que, junto com o factual, não deve simplesmente ser esquecido". (Heisenberg, 2005a, p. 82). Segundo Einstein, Mach teria negligenciado o caráter real da simplicidade da natureza e seu conceito de "economia do pensamento" possuiria 
"uma coloração por demais subjetiva: na verdade, a simplicidade das leis da natureza é também um fato objetivo e trata-se de, em uma construção conceitual correta, colocar em um justo equilíbrio os lados subjetivo e objetivo da simplicidade" (Einstein apud Heisenberg, 2005a, p. 80).

No diálogo entre Heisenberg e seus colegas, Wolfgang Pauli já havia notado essa limitação do método de Mach. A dificuldade em perceber a realidade dos conceitos e formulações da física, restringindo-os a uma mera descrição pragmática de dados empíricos com vistas a prever determinados fenômenos, teria feito que Mach negasse a existência do átomo, justamente porque a realidade atômica foge à nossa intuição empírica.

Segundo Pauli, Newton não teria partido do princípio da economia do pensamento e achado uma solução mais simples que a de Ptolomeu para calcular o movimento dos corpos celestes, mas teria antes introduzido um novo modo de questionamento da natureza. Em comparação com a física ptolomaica, mais presa à descrição empírica dos fenômenos, a física newtoniana perguntara pela causa do movimento dos planetas, introduzindo o conceito de força gravitacional e possibilitando uma apreensão e descrição matemáticas da natureza. Seria esse modo novo de questionar, e não o princípio de economia do pensamento, que permitiria remeter o complexo movimento dos planetas a uma fórmula simples e universal, aplicável aos corpos em geral e não apenas ao movimento dos corpos celestes. Entender seria essa "remissão da variedade multiforme ao geral e ao simples" ou, como já diziam os gregos, "do 'Múltiplo' ao 'Uno'. A habilidade de prever é uma consequência de entender, de possuir conceitos corretos, mas não é simplesmente idêntica ao entender" (Heisenberg, 2005a, p. 46).

Porém Pauli reconhece que a relação entre os conceitos da física e a realidade da natureza se torna mais complexa quando investigamos a estrutura do átomo. Como se sabe, o modelo atômico adotado por Niels Bohr buscava resolver algumas inconsistências do assim denominado modelo planetário, proposto pelo físico inglês Rutherford. Nesse último, o átomo é representado como constituído de um núcleo em torno do qual os elétrons giram à semelhança dos planetas em torno do sol. Entretanto, tal representação se mostra problemática. Torna-se questionável a própria existência de uma órbita do elétron em torno do núcleo. Conseguimos observar a trajetória de um elétron, por exemplo, em uma câmara de nuvens, ${ }^{6}$ mas não podemos observar diretamente seu comportamento no átomo. O modelo atômico proposto por Rutherford nos remete intuitivamente aos princípios da física clássica, os quais são insuficientes para explicar a estabilidade do átomo. Segundo as leis clássicas do eletromagnetismo, toda

6 A câmara de nuvens, ou câmara de Wilson (inventada em 1897 pelo físico inglês Charles Wilson), é um dispositivo que permite observar o rastro deixado por partículas subatômicas por meio da ionização do gás presente no seu interior. 
carga elétrica, quando acelerada, irradia energia. Assim, o elétron deveria perder energia até se chocar com o núcleo. Porém o que se observa é que um átomo pode sofrer uma série de alterações, pode receber ou perder energia e reagir com outros átomos e, entretanto, conservar sempre as mesmas propriedades. Assim, a principal dúvida de Heisenberg e Pauli no início de seus estudos era a relação entre o modelo atômico de Bohr e a estabilidade do átomo.

Heisenberg obteve uma primeira resposta às questões acima do próprio Bohr quando, em 1922, foi convidado por Sommerfeld para assistir a uma série de preleções do físico dinamarquês na cidade alemã de Göttingen. Durante o encontro, Niels Bohr convidou o jovem estudante para um passeio na tarde do dia seguinte após uma das preleções. Segundo Heisenberg: "esse passeio exerceu a mais forte influência em meu desenvolvimento científico posterior, ou talvez seja melhor dizer que meu desenvolvimento científico propriamente dito apenas teve início com esse passeio" (Heisenberg,

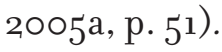

Durante a caminhada, Bohr teria dito que reconhecia as falhas de seu modelo atômico, cuja analogia com um sistema planetário não deveria ser tomada de modo literal. Para o físico dinamarquês, explicar a realidade atômica envolve uma dificuldade peculiar na história da ciência. As ciências naturais costumam apoiar-se em conceitos e métodos já disponíveis a fim de explicar novos fenômenos, remetendo-os a leis e processos já conhecidos. Entretanto, os conceitos clássicos que se encontram à disposição dos físicos são insuficientes para explicar os fenômenos que ocorrem no nível atômico. Precisamos falar da estrutura do átomo, mas não possuímos uma linguagem apropriada. Assim, ao ser questionado sobre o significado de seu modelo atômico, Bohr teria respondido:

Essas imagens foram, sim, deduzidas ou, se o senhor preferir, elas foram adivinhadas a partir de experiências e não conquistadas mediante meros cálculos teóricos. Espero que essas imagens descrevam tão bem a estrutura do átomo e, precisamente, apenas tão bem quanto seja possível descrevê-la na linguagem intuitiva da física clássica. Nós devemos ter claro que aqui a linguagem só pode ser utilizada de modo semelhante à poesia, na qual não se trata de representar precisamente um estado de coisas, mas antes de criar imagens e gerar associações intelectuais na consciência do ouvinte (Heisenberg, 2005a, p. 54).

A relação entre a nossa linguagem e a objetividade da natureza constitui um dos problemas fundamentais da assim denominada "Escola de Copenhague". Segundo Bohr: "o significado da ciência física para a filosofia não reside meramente no constante aumento em nossa experiência da matéria inanimada, mas, sobretudo, na opor- 
tunidade de testar os fundamentos e o alcance de alguns de nossos conceitos mais elementares" (Bohr, 1963, p.17).

Antes de comentarmos alguns dos problemas filosóficos e epistemológicos discutidos pela Escola de Copenhague, faz-se necessário traçar um breve histórico da relação entre a mecânica quântica e a teoria atômica.

\subsection{O Quantum de aÇÃo de Planck E a física atômica}

Como se sabe, a mecânica quântica tem suas origens na virada do século xx, a partir dos estudos do físico alemão Max Planck sobre termodinâmica, mais precisamente sobre a radiação emitida por um corpo negro. ${ }^{7}$ À época, um dos grandes problemas da termodinâmica dizia respeito à transmissão da radiação térmica. As teorias dominantes, segundo as quais um corpo poderia emitir ou absorver energia de modo contínuo e indefinidamente, mostravam-se insuficientes para descrever alguns experimentos empíricos, sendo muitas vezes refutadas pelos fatos. Não cabe aqui nos aprofundarmos nas teorias e experimentos que antecederam a descoberta de Planck. Para os nossos objetivos, basta indicar certos aspectos dessa descoberta que nos ajudarão a compreender algumas das rupturas produzidas pela mecânica quântica no pensamento clássico.

Dito de modo sumário, em 1901 Planck propôs que a transmissão de energia se daria de modo discreto (e não contínuo como se pensava anteriormente) na forma de pacotes, ou quanta de energia. No caso da radiação térmica, o valor mínimo de um quantum de energia transmitida, também denominado de quantum de ação, é expresso pelo produto da frequência ( $v$ ) da onda eletromagnética (luz e calor) pela constante de Planck (h): E= vh, onde h é igual a 6,626 x 10 $0^{-34} \mathrm{~J} / \mathrm{s}$ (joules por segundo). Assim, os átomos (então designados por Planck como osciladores) no interior do corpo negro só poderiam absorver e emitir energia em quantidades discretas e limitadas, obedecendo ao valor expresso na fórmula de Planck. Como o quantum de ação é da ordem de $10^{-34}$, ele torna-se imperceptível no nível da nossa experiência cotidiana, mas não pode ser negligenciado na análise dos fenômenos que ocorrem em escalas muito pequenas.

Em 1905, Einstein utilizou a descoberta de Planck para explicar o efeito fotoelétrico, ou seja, o fato de a luz poder arrancar elétrons de uma superfície metálica. Segundo ele, a luz também se propagaria através de quanta de energia, denominados de fótons. Dependendo da frequência da luz emitida, um fóton teria energia suficiente

${ }_{7} \mathrm{O}$ corpo negro é um objeto hipotético que absorveria toda radiação que incidisse sobre ele. Na prática, um forno hermeticamente isolado, que não troca energia com o exterior, e com uma pequena abertura pela qual a energia gerada em seu interior é emitida (tal qual utilizado por Max Planck em seus experimentos), aproxima-se do conceito de corpo negro. 
para "chocar-se" com o elétron e arrancá-lo do átomo. A descoberta de Einstein, que lhe rendeu o prêmio Nobel em 1921, implica um questionamento sobre a própria natureza da luz que pode comportar-se como uma partícula (uma substância limitada a um volume diminuto), como no caso do efeito fotoelétrico, ou como uma onda (um campo que se propaga em um vasto espaço), como quando verificamos os fenômenos da difração ou da interferência. ${ }^{\mathbf{8}}$

A explicação de Einstein sobre o efeito fotoelétrico corrobora o fato de que a hipótese de Planck não se restringe ao problema da irradiação de calor, devendo ser tomada como uma lei fundamental da natureza. Assim, em 1913, a fim de estabelecer um nexo entre o modelo de Rutherford e o fato da estabilidade da matéria, Bohr introduziu a ideia dos níveis estacionários de energia, inspirado na teoria do quantum de ação. Se a alteração de energia no átomo ocorre mediante porções discretas, então o átomo também deveria existir em níveis estacionários de energia. Assim, o átomo possuiria um nível mínimo de energia no qual ele se encontraria em seu estado "natural", ao qual ele sempre retornaria após perder energia. No caso do elétron, poderíamos dizer, em uma ilustração intuitiva, que seu "lugar natural" seria aquele mais próximo ao núcleo, no qual ele possuiria seu limite mínimo de energia. Quando um elétron recebe energia, ele salta de uma camada mais interna à outra mais externa, retornando sempre ao nível mais baixo e emitindo a energia excedente em forma de luz. Isso expressaria o fato de um elétron nunca chocar-se com o núcleo.

Após as descobertas de Planck, Einstein e Bohr, seguiu-se um intenso debate em torno da teoria quântica, sobretudo na segunda metade dos anos vinte. Em 1923, o físico norte-americano Arthur Compton comprova o caráter corpuscular da luz mediante experiências com raios X. Em 1924, o francês Louis-Victor de Broglie identifica a dualidade onda-partícula também no comportamento do elétron e das demais partículas sub-atômicas, transformando-a em um dos problemas fundamentais da física quântica. Em 1925 Heisenberg elabora, com a ajuda de Max Born e Pascual Jordan, a assim denominada mecânica matricial, como uma primeira tentativa de descrever matematicamente os fenômenos quânticos. Em 1926, Erwin Schrödinger desenvolve a mecânica ondulatória. Em 1927 ocorre a famosa conferência de Solvay, na qual se reúnem os maiores nomes da física moderna (ver figura 1). Essa conferência é o marco onde se consolidam as principais interpretações da mecânica quântica no final dos anos vinte, dentre as quais nos concentraremos, como dissemos, na escola de Copenhague.

8 Difração é um fenômeno ondulatório que consiste no desvio da trajetória de uma onda ao contornar um objeto ou passar por um orifício cujas dimensões sejam da mesma ordem de grandeza do comprimento da onda. A interferência é a superposição da amplitude de duas ondas que se encontram. A interferência pode ser construtiva, quando duas ondas estão em fase e produzem uma onda maior. A interferência é destrutiva quando duas ondas possuem fases invertidas e se anulam. 


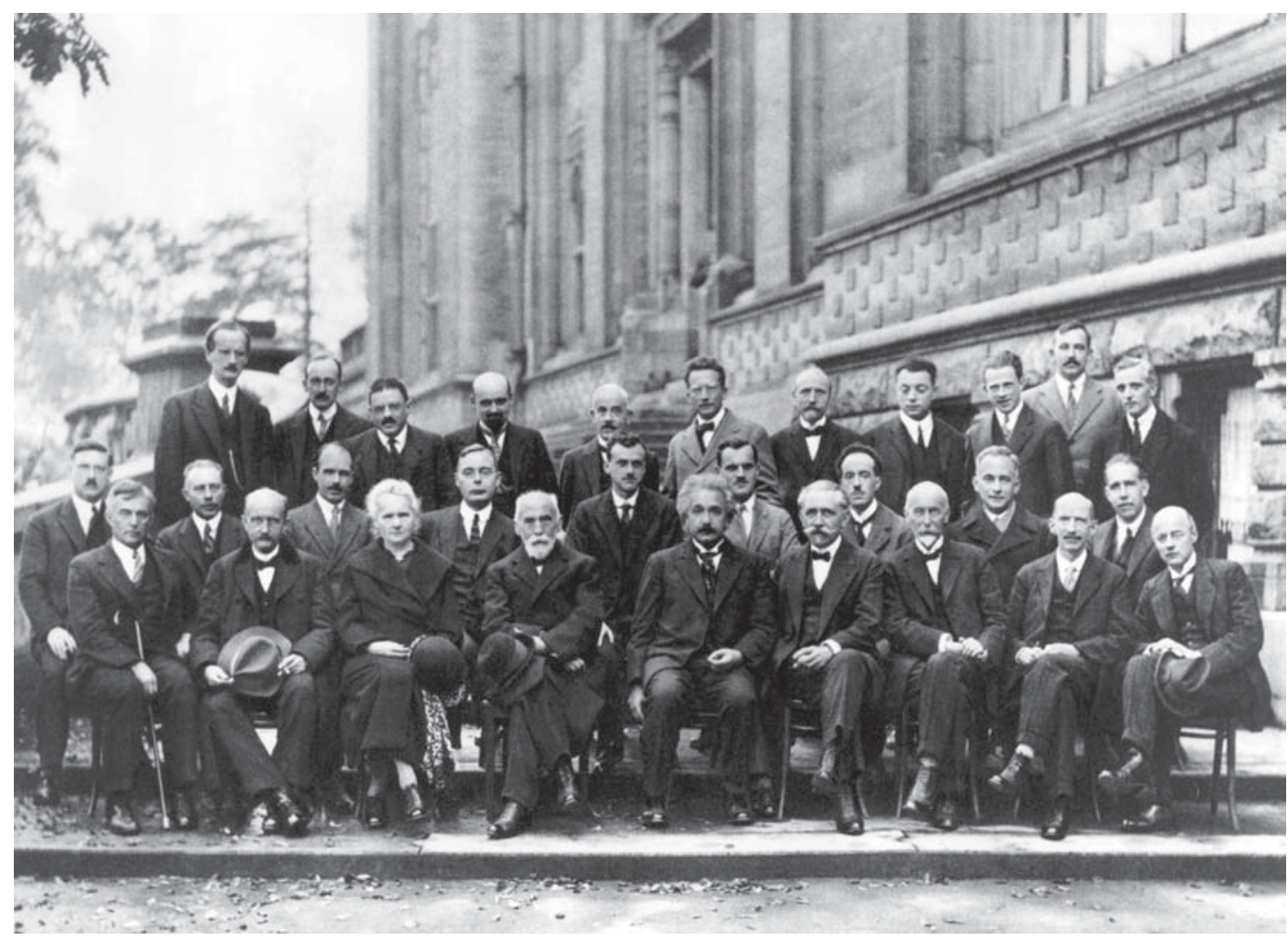

Figura 1. A Conferência de Solvay de 1927 faz parte de uma série de conferências iniciadas pelo industrial Belga Ernest Solvay (1838-1922) que criou em Bruxelas um fórum para discutir problemas científicos. Em pé, da esquerda para direita: A. Piccard, E. Henriot, P. Ehrenfest, E. Herzen, T. de Donder, E. Schrödinger, J. E. Verschaffelt, W. Pauli, W. Heisenberg, R. H. Fowler, L. Brillouin. No centro, sentados, da esquerda para direita: P. Debye, M. Knudsen, W. L. Bragg, H. A. Kramers, P. A. M. Dirac, A. H. Compton, L. de Broglie, M. Born, N. Bohr. Na frente, da esquerda para direita: I. Langmuir, M. Planck, M. Skodowska-Curie, H. A. Lorentz, A. Einstein, P. Langevin, C.--E. Guye, C. T. R. Wilson, O. W. Richardson.

\subsection{A escola de Copenhague: Gomplementaridade e incerteZa}

Segundo Heisenberg, a escola de Copenhague parte de um paradoxo que pode ser formulado da seguinte maneira: todo experimento físico deve ser descrito com os conceitos da física clássica, forjados a partir de uma linguagem adaptada à nossa experiência intuitiva das coisas no espaço e no tempo. As perguntas que dirigimos à natureza, mediante os experimentos e aparatos com os quais a investigamos, são feitas sobre essa base conceitual e linguística, haurida da nossa realidade circundante. Sem o uso dessa linguagem não poderíamos nos comunicar e transmitir o conhecimento obtido, comprometendo assim a própria objetividade científica. Entretanto, a tentativa de descre- 
ver os fenômenos quânticos com conceitos clássicos parece conduzir a uma série de contradições que subvertem a própria experiência intuitiva sobre a qual esses conceitos foram produzidos (Heisenberg, 2006, p.42).

Assim, o início da década de 1920 é marcado, por um lado, pela tentativa de elaborar um formalismo matemático que pudesse representar as descontinuidades presentes nos fenômenos quânticos e, por outro lado, pela dificuldade em obter uma interpretação dos fenômenos atômicos que pudesse ser expressa intuitivamente mediante os conceitos da física clássica. A primeira tentativa nesse sentido foi a criação da mecânica matricial elaborada por Heisenberg, Jordan e Born em 1925. Essa nova mecânica tinha o mérito de dar conta de um grande número de dados experimentais, embora fosse combatida por muitos cientistas, em especial pelo físico austríaco Erwin Schrödinger, por seu caráter pouco intuitivo (unanschaulich) ${ }^{9}$ (cf. Mehra, 1987, p. 478), ou seja, por impossibilitar descrever os dados observáveis enquanto fenômenos que obedecessem a leis causais contínuas no espaço e no tempo (cf. Hilgevoord \& Uffink, 2012, p. 3).

Em resposta à mecânica matricial de Heisenberg, Schrödinger propõe em 1926 sua mecânica ondulatória, a qual proporcionava uma descrição mais intuitiva dos fenômenos atômicos que podiam ser explicados mediante funções de onda. O formalismo matemático proposto por Schrödinger teve uma rápida aceitação na comunidade científica, apesar dos protestos de Heisenberg. Este último opusera-se desde o início à mecânica ondulatória, objetando, dentre outras coisas, que ela não explicava as descontinuidades presentes nas leis de Planck sobre a irradiação de energia (cf. Blum; Dürr \& Rechenberg, 1985, p. 514-7; Jammer, 1974, p. 56).

A repercussão causada pela teoria de Schrödinger levou Bohr e Heisenberg a convidá-lo a expor e discutir sua mecânica ondulatória para a sociedade de física de Copenhague. Apesar de haver uma correspondência entre os formalismos das mecânicas ondulatória e matricial, à época existia uma grande divergência entre as interpretações de Heisenbreg e Schrörendiger sobre o significado físico do arcabouço matemático da teoria quântica. ${ }^{10}$

9 A palavra alemã Anschaung, da qual surge o adjetivo anschaulich, pode ser traduzida por "intuição" no sentido (kantiano) da percepção de algo em uma relação de espaço e tempo mediante relações de causalidade. Como veremos adiante, Heisenberg dará outra definição a essa palavra a fim de rebater as críticas que acusavam a teoria quântica de ser excessivamente abstrata e contraintuitiva (unanschulich).

10 Em uma carta de 1926 a Pauli, Heisenberg se refere à mecânica ondulatória como sendo um lixo e detestável (cf. Mehra, 1987, p. 483). Segundo relato de Heisenberg, Schrödinger teria dito, a respeito da hipótese de Bohr sobre o salto quântico, o seguinte:" Se ainda devemos insistir nesse maldito salto quântico, então me arrependo de ter alguma vez me ocupado com a teoria quântica" (Heisenberg apud Blum; Dürr \& Rechenberg, 1984, p. 436). Como se sabe, em 1930 Neumann irá demonstrar de modo claro a correspondência entre as mecânicas matricial e a ondulatória (cf. Jammer, 1974, p. 22). 
A confrontação com a mecânica de Schrödinger levou a um debate intenso entre Heisenberg e Bohr acerca de uma teoria quântica que pudesse servir a uma explicação física coerente dos dados experimentais (cf. Jammer, 1974, p. 57), resultando na formulação de dois princípios fundamentais elaborados pela escola de Copenhague a partir de 1927, quais sejam: o princípio de incerteza de Heisenberg e o princípio de complementaridade de Niels Bohr.

Heisenberg apresenta seu "princípio de incerteza"11 pela primeira vez em um artigo de 1927 intitulado: "Über den anschaulichen Inhalt der quantentheoretischen Kinematik und Mechanik". Em uma livre tradução para o português o título pode ser escrito da seguinte maneira: "Sobre o conteúdo intuitivo (anschaulich) da cinemática e da mecânica na teoria quântica". Logo no início do artigo, Heisenberg define o que compreende por "conteúdo intuitivo":

Acreditamos compreender intuitivamente uma teoria física quando nós, em cada caso particular, podemos pensar qualitativamente as consequências experimentais dessa teoria e quando nós ao mesmo tempo reconhecemos que a aplicação dessa teoria não contém nenhuma contradição. (...) A mecânica quântica surgiu precisamente da tentativa de romper com os conceitos cinemáticos familiares e, no lugar deles, estabelecer relações entre quantidades concretamente dadas na experiência. Como isso parece ter sido alcançado, o esquema matemático da teoria quântica não necessita de revisão (Heisenberg, 1927, p. 172).

Esse esquema matemático fora obtido pela aplicação das leis de transformação de Dirac e Jordan à mecânica matricial ${ }^{\mathbf{1 2}}$ e é a partir dele que Heisenberg deduz, na segunda parte do artigo de 1927, as relações de indeterminação mais tarde batizadas de "princípio de incerteza". Como se sabe, o formalismo diz que em um sistema quântico não se pode determinar simultaneamente com precisão o valor de duas grandezas canônicas conjugadas (Heisenberg, 1927, p. 179), sendo que o produto entre elas não pode ser inferior à constante de Planck (h) dividida por $2 \pi$. As grandezas conjugadas

11 A expressão “princípio de incerteza” não é utilizada por Heisenberg no artigo de 1927 e é pouco usada por ele em textos posteriores. Ela teria sido cunhada, provavelmente, pelo físico inglês Arthur Eddingon em 1928 (cf. Hilgevoord \& Uffink, 2012, p. 9), tornando-se popular nos textos em inglês. Heisenberg normalmente utiliza a expressão "relação de indeterminação" (Unbestimmtheitsrelation) ou "relação de imprecisão" (Ungenauigkeitsrelation). No artigo de 1927 a palavra incerteza Unsicherheit é utilizada apenas no apêndice (escrito após algumas ressalvas feitas por Bohr ao artigo), mas sem relacioná-la à palavra "princípio" (cf. Jammer, 1974, p. 61.) Não obstante, utilizaremos a expressão "princípio de incerteza", por ser um termo amplamente aceito e difundido na literatura sobre o assunto. 12 Não cabe aqui reproduzir as explicações matemáticas do "princípio de incerteza". Para um melhor detalhamento de como Heisenberg deduz as relações de indeterminação a partir das teorias de transformação de Dirac e Jordan, ver, além da segunda parte do artigo de Heisenberg de 1927, também as seções 7 e 8 de Mehra, 1987, p. 490-7. 
pelas quais o princípio de incerteza é mais conhecido são o momento (p) e a posição (q), assim: $\delta p \delta q ~ e^{" ~ h / 2 \pi . ~} .^{\mathbf{3}}$

Vimos que Heisenberg procura atribuir um caráter intuitivo a esse formalismo matemático. Segundo a passagem acima citada, uma teoria é tida como intuitiva não pela possibilidade de explicar os fenômenos físicos mediante relações causais contínuas no espaço e no tempo, como na mecânica ondulatória de Schrödinger. O caráter intuitivo de uma teoria se deve, por um lado, ao fato de que as consequências experimentais dela extraídas possam ser pensadas sem contradições. Por outro lado, uma teoria evita contradições quando edificada a partir da tentativa de descrever relações entre grandezas concretamente observáveis nos experimentos.

Assim Heisenberg busca esclarecer intuitivamente essas relações de indeterminação mediante um experimento mental que ficou conhecido como microscópio de raios $\gamma .{ }^{\mathbf{1 4}}$ Segundo ele, mesmo que houvesse um microscópio suficientemente desenvolvido que possibilitasse olhar diretamente o elétron em torno do núcleo, ainda assim seria impossível determinar simultaneamente com precisão sua velocidade e posição. Para que o elétron fosse visto, seria necessário lançar luz sobre ele. Suponhamos que nosso microscópio fosse sutil ao ponto de lançar apenas um fóton de luz sobre o elétron. A precisão com que veríamos o elétron seria tanto maior quanto menor fosse o comprimento de onda e, consequentemente, maior a frequência do fóton. Entretanto, como a energia do fóton aumenta com a frequência, esse quantum de luz se chocaria com o elétron, alterando seu movimento e deslocando-o de sua trajetória. Poderíamos localizar o elétron, mas não saberíamos nada sobre seu movimento. Segundo Heisenberg, mediante o experimento imaginário descrito acima "visualizamos uma explicação intuitiva direta da relação pq - qp = h/2 $\pi \mathrm{i}$ " (cf. Heisenberg, 1927, p. 175). A equação representa as leis de transformação de Dirac-Jordan a partir das quais foi deduzido o "princípio de incerteza". Uma consequência imediata das relações de indeterminação expressas na nova mecânica é o fato de o ideal clássico de causalidade e, consequentemente, de uma previsibilidade determinista dos fenômenos ficar ameaçado quando aplicado aos fenômenos quânticos.

Segundo o ideal determinista da física clássica, se conhecermos as coordenadas iniciais de um sistema físico e possuirmos o esquema matemático correto de suas leis causais poderemos predizer o que ocorrerá com esse sistema em um tempo futuro. Já em um sistema quântico, as relações de indeterminação fazem que as coordenadas

13 Essa relação vale também para as demais grandezas conjugadas como tempo e energia ( $\delta \mathrm{t} \delta \mathrm{E} \geq \mathrm{h} / 2 \pi)$ e momento angular e fase $(\delta w \delta \mathrm{j} \geq \mathrm{h} / 2 \pi)$.

14 Heisenberg expõe esse experimento mental, pela primeira vez, no texto de 1927 (cf. p. 174 ss.), retomando-o em várias outras ocasiões, por exemplo, em Heisenberg, 1949 e 2006. 
iniciais de um fenômeno atômico devam ser matematicamente descritas mediante funções de probabilidade, as quais não representam fenômenos efetivos, mas indicam antes possibilidades, tendências para que algo ocorra. Heisenberg compara essas funções de probabilidade à noção aristotélica de dynamis, no sentido de uma potência a ser realizada (cf. Blum; Dürr \& Rechenberg, 1984, p. 208).

Por exemplo, para "observarmos" a trajetória de um elétron devemos, primeiramente, determinar a sua posição em um instante dado. Com isso não conseguiremos saber com precisão sua velocidade, mas podemos calcular a probabilidade de ele se encontrar em uma determinada região no instante seguinte. Porém a passagem da potência ao ato, ou seja, o lugar onde o elétron efetivamente se encontrará em um instante seguinte, só se realiza quando uma nova medição for feita. Em uma interpretação clássica, diríamos que, entre uma medição e outra, o elétron deve ter percorrido um determinado caminho. Porém, segundo Heisenberg, tal afirmação seria um mau emprego dos conceitos clássicos. Não podemos dizer o que efetivamente aconteceu com o elétron entre uma medição e outra, a própria ideia de uma trajetória torna-se problemática. Apenas verificamos que ele "saltou" de uma posição para outra. Esse salto quântico não implica uma relação de causalidade em um esquema espaço-temporal, mas antes a realização, durante a observação, de uma potencialidade em meio a um conjunto de possibilidades (cf. Heisenberg, 2006, p. 44-5). Sobre essa ruptura da física quântica com o ideal clássico de causalidade, Heisenberg diz, no final do seu artigo de 1927, o seguinte:

Mas na formulação acurada da lei de causalidade: "quando conhecemos exatamente o presente, podemos calcular o futuro", não é a conclusão, mas sim a premissa que está errada. Por princípio nós não podemos conhecer o presente em todos os seus elementos determinantes. Por isso toda observação é uma escolha entre uma abundância de possibilidades e uma restrição de possibilidades futuras. $\mathrm{O}$ fato de o caráter estatístico da teoria quântica estar estreitamente ligado à inexatidão (Ungenauigkeit) de toda observação poderia conduzir à suposição de que por trás do mundo estatisticamente observado haveria ainda um mundo "real", no qual a lei de causalidade valesse. Mas tal afirmação nos parece, e nós assinalamos isso enfaticamente, infrutífera e sem sentido. A física deve apenas descrever formalmente os nexos do que é observado. Podemos antes caracterizar muito melhor o verdadeiro estado de coisas dizendo: porque a experiência está submetida às leis da mecânica quântica, então mediante a mecânica quântica fica estabelecida definitivamente a invalidade da lei causal (Heisenberg, 1927, p. 197). 
A relação entre as indeterminações dadas pelo esquema matemático da mecânica quântica e, ao mesmo tempo, a exigência de que uma teoria deva ater-se ao que é concretamente observável, tal como fora apresentada no artigo de 1927, é responsável por uma polêmica, até hoje presente, acerca do estatuto do princípio de incerteza. Trata-se de saber se as relações de indeterminação podem ser consideradas como intrínsecas à teoria quântica, ou seja, se elas são princípio aplicável a toda experiência possível, ou se elas decorrem apenas do processo de medição dos dados observáveis.

Por exemplo, em um artigo publicado recentemente por cientistas canadenses o princípio de incerteza é abordado mediante dois aspectos. O primeiro, tido como atualmente aceito e incontestável, toma o princípio em questão como intrínseco a todo sistema quântico, cuja comprovação é independente de qualquer medição específica. Entretanto, esse caráter intrínseco não é atribuído diretamente a Heisenberg, e sim aos aperfeiçoamentos das relações matemáticas de indeterminação feitos posteriormente por Kennard em 1927, Wyl em 1928 e Robertson em 1929. Segundo o artigo, em 1927 Heisenberg teria pensado seu princípio de incerteza apenas em relação às imprecisões e às distorções causadas pelos processos de medição: “Aqui, Heisenberg seguiu o exemplo de Einstein e tentou basear a nova teoria física apenas em quantidades observáveis, ou seja, apenas nos resultados de medições" (Rozema et al., 2012, p. 1). Essa segunda versão do princípio de incerteza é contestada experimentalmente nesse artigo através de um experimento envolvendo medições fracas.

Entretanto, outros autores como Jammer (1974, p. 57) e Mehra (1987, p. 495) lembram que se Heisenberg aprendera com Einstein que uma teoria deve ser baseada apenas em grandezas observáveis, o próprio Einstein também lhe dissera, como já indicamos na seção 2 desta introdução, que "apenas a teoria decide sobre o que pode ser observado". 15 Para Jammer o princípio de incerteza formulado por Heisenberg em 1927 é "uma consequência matemática imediata do formalismo da mecânica quântica, mais precisamente da teoria da transformação de Dirac e Jordan” (1974, p. 60). Assim, a origem conceitual do princípio de incerteza envolveria uma dupla questão: (1) saber se o formalismo matemático possibilita o fato de que variáveis conjugadas são determináveis em um momento dado apenas com uma precisão limitada; (2) uma vez comprovada teoricamente essa imprecisão, seria necessário saber se ela é compatível com o máximo de acuidade obtida pelos instrumentos de medida (cf. Jammer, 1974, p. 61).

Segundo essa interpretação, a teoria parece ser anterior aos dados experimentais e o microscópio de raios $\gamma$ é visto como um experimento mental destinado a com-

15 Em um artigo intitulado "Observações sobre a gênese da relação de indeterminação", escrito um ano antes de sua morte (1975), Heisenberg cita o comentário de Einstein ao qual nos referimos acima e afirma que ele fora de fundamental importância para a descoberta das relações de indeterminação (cf. Blum; Dürr \& Rechenberg, 1985, p. 514,-7). 
provar e dotar a teoria de um caráter intuitivo. Essa precedência da teoria sobre a experiência parece ser corroborada pelo próprio Heisenberg em uma entrevista na qual resume as divergências entre ele e Bohr que precederam à elaboração dos princípios de incerteza e de complementaridade:

O ponto fundamental era que Bohr queria tomar o dualismo entre onda e partícula como o cerne do problema. Eu [por outro lado] diria: "nós possuímos um esquema matemático consistente e ele nos diz tudo que pode ser observado. Não há nada na natureza que não possa ser descrito por esse esquema matemático". Havia um modo diferente de olhar para o problema porque Bohr não gostava de dizer que a natureza imita o esquema matemático, que a natureza só faz coisas que se encaixam no esquema matemático (Heisenberg apud Mehra, 1987, p. 496).

Embora no texto de 1927 a preponderância do formalismo matemático não seja tão evidente quanto nos escritos tardios de Heisenberg, parece precipitado dizer que ele primeiramente formulou seu princípio de incerteza considerando apenas as distorções causadas pelos instrumentos de medição. Não obstante a isso, a interação entre o arranjo experimental e o objeto observado ocupa um lugar de destaque nos textos de Heisenberg, constituindo-se como um dos problemas centrais abordados pela escola de Copenhague. Uma das principais consequências de tal interação é a ruptura com a divisão cartesiana clássica entre sujeito e objeto.

Com efeito, a física clássica parte da certeza de que os fenômenos físicos são eventos que ocorrem em um esquema espaço-temporal, cujas leis causais podem ser matematicamente descritas como expressão de uma realidade que independe de qualquer observação. Mesmo que o acesso a essas leis dependa de experimentos de alta complexidade técnica, a física clássica acredita ser sempre possível descontar as distorções causadas pelos aparelhos de medição e descrever a natureza tal qual ela efetivamente é.

Já no nível atômico, o aparato conceitual e técnico utilizado para penetrar nessa região diminuta da natureza não apenas provoca alterações irreversíveis no objeto investigado como também determina suas características. ${ }^{\mathbf{1 6}}$ Essa impossibilidade de compensar o efeito causado pelo experimento no objeto não reside em uma falha de nosso entendimento e nem no fato de ainda não possuirmos uma aparelhagem técnica suficientemente desenvolvida para investigar o que realmente ocorreria no átomo. A própria natureza do átomo, e de todo fenômeno onde o quantum de ação de Planck não pode ser negligenciado, impossibilita uma separação radical entre sujeito e objeto. Assim, a objetividade da natureza no nível quântico torna-se indissociável dos apa- 
ratos técnicos que utilizamos para investigá-la e da linguagem com a qual a descrevemos. "Nós devemos nos lembrar que aquilo que observamos não é a natureza ela mesma, mas a natureza que é submetida ao nosso modo de questionamento" ( Heisenberg, 2006, p. 60-1).

Vemos que o papel do observador é decisivo para se estabelecer as propriedades de um sistema quântico, e isso de um modo radicalmente distinto daquele da física clássica. Para essa última, podemos descobrir as propriedades de um determinado objeto mediante a repetição de um mesmo experimento ou combinando diversos experimentos para nos certificarmos de suas características. Assim, os vários resultados obtidos são suplementares e nos ajudam a obter uma imagem consistente do objeto.

Já na investigação dos objetos quânticos, a interação entre os instrumentos de medida e o objeto exige uma nova forma de abordagem dos fenômenos. Se tomarmos como exemplo a dualidade onda-partícula, central para a elaboração do princípio de complementariadade de Bohr, veremos que tanto nossa linguagem quanto nossos experimentos impedem que tenhamos em uma mesma imagem a representação de algo como sendo simultaneamente onda e partícula. Dizer que algo é e não é a mesma coisa ao mesmo tempo fere o princípio lógico de contradição. Entretanto, alguns experimentos podem nos mostrar um elétron na forma de onda, enquanto outros revelamno como uma partícula. Para Bohr, essas duas determinações são complementares. Dependendo do arranjo experimental e da pergunta com a qual nos dirigimos à natureza, uma "partícula" subatômica pode apresentar um comportamento ondulatório ou corpuscular. Para Bohr o que decide sobre quais propriedades um objeto quântico pode apresentar é, no limite, o próprio observador. Isso não implicaria uma limitação na investigação da natureza, mas antes um modo de inquirição adequado ao mundo quântico: "longe de restringir nossos esforços em questionar a natureza, a noção de complementaridade simplesmente caracteriza as respostas que podemos obter com esse modo de questionamento sempre que a interação entre os instrumentos de medida e os objetos formar uma parte integral do fenômeno" (Bohr, 1963, p. 4).

O princípio de complementaridade rompe com alguns pressupostos do positivismo com relação ao uso e à formação dos conceitos. Assim, Heisenberg relata uma conversa que tivera com Bohr e Pauli em 1952, na qual o físico dinamarquês esclarece sua posição diante do positivismo (cf. Heisenberg, 2005a, p. 241-55). Segundo ele, o positivismo teve o mérito de romper com os métodos antigos de investigação da natureza e com as explicações religiosas e supersticiosas do mundo, impondo a necessidade da verificação empírica dos fenômenos e de clareza conceitual em sua explicação. Entretanto, com isso, o positivismo impôs uma restrição aos conceitos e aos assuntos mais genéricos que não se referem diretamente ao que se verifica na experiência, classificando-os como resquícios de uma metafísica a ser superada. 
Bohr lembra aos outros dois físicos de um encontro filosófico em Copenhague no qual estavam presentes alguns adeptos da escola de Viena. O físico dinamarquês conta ter estranhado o fato de, após ter exposto alguns dos princípios da teoria quântica, nenhuma pergunta ou objeção lhe ter sido feita: "pois é impossível alguém ter compreendido a teoria quântica, sem antes ter se espantado com ela" (Heisenberg, 2005a, p. 2411). Para Pauli, essa falta de espanto poderia ser atribuída ao fato de os positivistas terem se contentado com as explicações logicamente coerentes da teoria quântica que possibilitam certo grau de previsibilidade nos resultados empíricos. Questões de cunho filosófico, como os princípios de complementaridade e de incerteza, ou problemas relativos ao papel do observador seriam desprezados, pois remeteriam a uma visão pré-científica da natureza. Bohr completa dizendo que, embora concordasse com a necessidade de clareza conceitual e verificação empírica, a restrição dos positivistas aos conceitos genéricos e às aproximações imagéticas ou alegóricas impediria qualquer avanço na teoria quântica. Citando uma passagem do poema de Schiller, "A sentença de Confúcio", segundo a qual "só a plenitude conduz à clareza, a verdade mora no abismo", Bohr diz que os positivistas possuem a técnica correta para evitar os erros, mas não para se precipitar em direção à verdade.

Se compararmos as interpretações da teoria quântica de Bohr e Heisenberg, em um primeiro momento parece correto afirmar, como o faz Karl Popper, que o programa epistemológico desse último era expurgar as interpretações do físico dinamarquês das magnitudes "não observáveis", purificando-as de toda inferência metafísica. Daí, por exemplo, a impossibilidade de se afirmar a existência de uma trajetória do elétron em torno do núcleo, visto que a órbita do elétron não pode ser experimentalmente observável. ${ }^{17}$ Entretanto, não é menos verdade que o físico alemão progressivamente incorpora elementos metafísicos em sua interpretação da teoria quântica. Assim, em uma conversa reservada com Pauli, Heisenberg afirma não concordar inteiramente com Bohr a respeito da necessidade de se evitar temas antigos nas ciências da natureza. Ao contrário, segundo ele, a física quântica retoma a antiga discussão entre materialistas e idealistas, remetendo, sobretudo, à disputa entre Platão e os atomistas (cf. Heisenberg, 2005a, p. 248 ss.).

Admirador do Timeu desde a juventude, Heisenberg acredita que Platão, e antes dele a escola pitagórica, descobrira uma relação fundamental entre a matemática e a natureza ao atribuir uma estrutura geométrica aos quatro elementos fundamentais que compõem o mundo material. Assim, a menor porção do elemento terra corresponderia

17 A afirmação de Popper sobre o programa epistemológico de Heisenberg é baseada em um escrito do físico alemão de 1929, Physikalische Prinzipien der Quantentheorie, no qual a postura antimetafísica de se evitar qualquer referência a grandezas não observáveis é bastante clara. 
ao cubo; a do elemento água ao icosaedro; do ar ao octaedro e do fogo ao tetraedro. Entretanto, alguns desses elementos poderiam ser divididos e reduzidos à forma única do triângulo. Logo, as partículas elementares, os átomos de Demócrito, teriam sua verdadeira realidade não no que é materialmente dado, mas nas ideias, nas formas matemáticas que os precedem.

Assim, podemos identificar um certo platonismo na interpretação que Heisenberg faz do formalismo da teoria quântica:

Quando sintetizamos os resultados de experimentos em uma fórmula e assim chegamos a uma descrição fenomenológica de um evento, como sempre se deve fazer na física teórica, temos o sentimento de nós mesmos havermos inventado essa fórmula. Porém, quando nos deparamos com essas simples e grandiosas conexões que finalmente são fixadas na axiomática, então tudo parece diferente. Aí surge, de uma vez, diante de nosso olho espiritual, um nexo que, mesmo sem nós, já sempre esteve aí e que manifestamente não foi feito pelo homem. Essas conexões são precisamente o conteúdo de nossa ciência. Nós somente podemos compreender efetivamente nossa ciência quando admitimos a existência de tais conexões (Heisenberg, 2005a, p. 120-1).

Vemos que, por um lado, Heisenberg assinala a necessidade de que toda teoria deva ser construída sobre evidências empíricas, evitando qualquer referência a elementos "não observáveis". Por outro lado, ele parece sugerir que as fórmulas e simetrias matemáticas, pelas quais representamos as potencialidades existentes na natureza, possuem não apenas uma anterioridade lógica, mas também ontológica sobre a efetividade do mundo material, chegando mesmo a se referir ao arcabouço matemático da física como uma relação entre o homem e aquilo que denomina de "a ordem central do mundo" (die zentrale Ordnung der Welt) (2005a, p. $25^{1} \mathrm{ss}$.).

Não cabe aqui nos aprofundarmos na complexa interpretação de Heisenberg da teoria quântica e em sua oscilação entre positivismo e um certo platonismo (cf. Leite \& Samuel, 2010). Nosso objetivo em expor algumas das posturas epistemológicas defendidas pela escola de Copenhague é o de simplesmente visualizarmos a perspectiva pela qual Heisenberg compara as concepções de natureza em Newton e Goethe. 


\title{
3 A teoria das Gores de Newton e Goethe À LUZ da física moderna
}

\author{
Cinza, fiel amigo, é toda a teoria, \\ e verde a áurea árvore da vida.
}

(Goethe, 1981, parte 1)

A retomada da discussão que Goethe estabelece com a óptica newtoniana se deve, em grande parte, ao fato de Heisenberg acreditar na atualidade e na urgência das objeções feitas pelo poeta ao crescente desenvolvimento das ciências da natureza e à necessidade de esclarecê-las à luz das novas descobertas da física moderna. Some-se a isso a crítica dos assim denominados "físicos alemães" que atribuíam o caráter abstrato da teoria quântica à sua origem judaica. As bases da física alemã podem ser vislumbradas em uma das passagens mais notórias do manual editado por Phillip Lenard em 1936, intitulado Física alemã em quatro tomos:

Alguém poderia perguntar: física alemã? Eu poderia ter dito também física ariana, ou física dos homens de tipo nórdico, física dos fundamentadores da realidade, dos perseguidores da verdade, dos fundadores das ciências da natureza. Alguns poderão contestar-me: "a ciência é e permanece internacional!" Mas aqui jaz um erro. Na verdade a ciência é, como tudo que o homem produz, determinada pela raça e pelo sangue (Lenard, 1936, p. xiv).

Para os autointitulados físicos arianos, a verdadeira ciência deveria ser aquela desenvolvida pelos homens nórdicos, cujas investigações baseavam-se em evidências empíricas. Desse modo, ao retomar as críticas de Goethe a Newton, Heisenberg conquista uma base histórica para discutir o problema do formalismo matemático nas ciências. As objeções de Goethe, tomado pelos físicos arianos como exemplo de homem nórdico, dizem respeito justamente ao caráter abstrato da física newtoniana, esta última incontestavelmente fundamentada na experiência (cf. Costa \& Videira, 2007).

Com efeito, para Heisenberg o que está em jogo na crítica de Goethe é o próprio valor das abstrações e do formalismo, cada vez menos intuitivos, com os quais descrevemos a natureza. É precisamente nesse abandono de um mundo intuitivamente apreensível, em direção a uma ciência da natureza cada vez mais abstrata, que reside, segundo Goethe, o caráter demoníaco da física clássica. Já no prefácio à Doutrina das cores, o poeta nos deixa claro qual ideia de natureza subjaz às suas investigações sobre as cores: 
Heisenberg e a doutrina das cores de Goethe e Newton

As cores são atos da luz, atos e afetos (Taten und Leiden). Nesse sentido, a partir delas podemos almejar obter esclarecimentos sobre a luz. Cores e luz relacionam-se entre si do modo mais estrito, mas devemos pensá-las como pertencentes à natureza como um todo: pois é a natureza toda que através delas quer revelar-se especialmente à sensibilidade do olho (...). Assim, a natureza fala decrescentemente a outros sentidos conhecidos, incompreendidos, desconhecidos; assim a natureza fala consigo mesma e conosco mediante milhares de fenômenos (Goethe, 2010, loc. 1037).

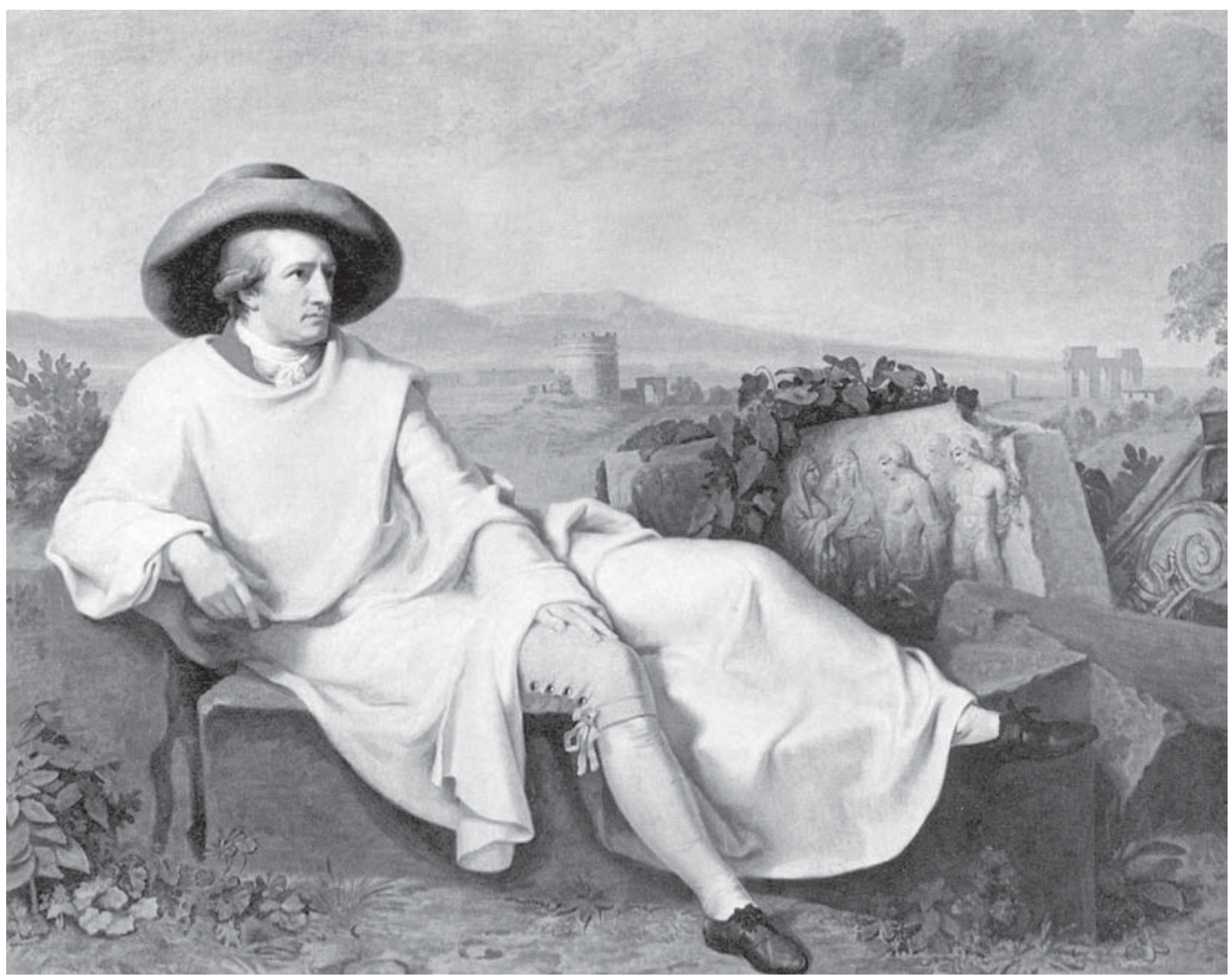

Figura 2. Tela retratando Goethe em ${ }_{17} 8_{7}$ na sua campanha pela Itália, país cujas paisagens lhe inspiraram escrever uma teoria das cores mais viva e intuitiva que a de Newton. O detalhe curioso dessa tela é que nela o poeta é retratado com dois pés esquerdos. 
Goethe acredita que a natureza em sua totalidade fala a nós através de nossos sentidos. Portanto, o ponto de partida de suas considerações científicas são as impressões sensíveis que intuímos imediatamente em nossa experiência do mundo circundante. Isso não significa que o poeta seja avesso a qualquer forma de abstração. Segundo ele, toda teoria sobre a natureza deve buscar nela um fenômeno originário (Urphänomen), a partir do qual a multiplicidade das aparições sensíveis possa ser compreendida. Em seu estudo sobre a morfologia das plantas, por exemplo, Goethe busca a planta originária (Urpflanze), ou seja, a forma originária com a qual a natureza produz a multiplicidade da vida vegetal. Na posse desse modelo o investigador da natureza poderia descobrir uma infinidade de plantas que "mesmo se não existissem, poderiam existir e possuir uma verdade e necessidade intrínsecas" (Goethe apud Heisenberg, 1971, p. 245). Também em seus estudos sobre mineralogia, Goethe acredita que o granito é a pedra originária (Urstein), fonte da multiplicidade das formações geológicas. As pequenas formações metálicas, raramente encontradas em algumas massas de granito, seriam a prova de uma dinâmica, de uma metamorfose presente desde a formação de cristais, "a primeira individuação bem sucedida da natureza", às mais elementares formas de vida vegetal, como os corais (Goethe, 2009, p. 212). Do mesmo modo, na sua Doutrina das cores, Goethe acredita ter descoberto o fenômeno originário da produção das cores na mistura entre o claro e o escuro, entre o luminoso e o turvo. ${ }^{\mathbf{8}}$

Portanto, Goethe reconhece que toda teoria implica certo grau de abstração e que não podemos conhecer a natureza sem identificarmos nela um fenômeno originário, sem remetermos a multiplicidade dos fenômenos a uma base comum. Até mesmo o uso da matemática e da geometria aparece nas considerações de Goethe sobre a natureza. Em suas análises sobre efeitos sensíveis e morais das cores, o poeta estabelece uma complexa ordem simétrica entre as cores, distribuindo-as em um hexaedro. Entretanto, ao mesmo tempo, o poeta assinala a necessidade de sermos prudentes e sabermos reconhecer os limites de nossa abstração:

Todo observar transforma-se em um considerar, todo considerar em um refletir, todo refletir em um associar e, assim, podemos dizer que, em cada olhar atento sobre o mundo, nós já teorizamos. Mas isso procedendo e agindo com consciência, com autoconhecimento, com liberdade e, para nos utilizarmos de uma palavra ousada, com ironia. Tal postura é necessária para que a abstração, que nós tememos, torne-se inofensiva e para que os resultados práticos que esperamos possam tornar-se vivos e úteis (Goethe, 2010, loc. 1078.).

18 Para saber mais detalhes sobre isso, ver a tradução aqui publicada da conferência de Heisenberg. 
Essa “abstração que nós tememos" é aquela que, desde Galileu, toma como o mais fundamental na natureza grandezas abstratas e matematicamente quantificáveis. Para Goethe, uma física como a newtoniana, que isola uma parte da natureza e a submete a uma série de experimentos para então explicá-los mediante abstrações matemáticas, estaria submetendo a totalidade "livre" e viva da natureza a uma "natureza" artificialmente produzida e aprisionada pelos instrumentos de observação. Logo, ele é coerente quando afirma que aquilo que o físico investiga, com suas fórmulas e experimentos, já não é a natureza.

Assim, o fenômeno originário de Goethe não deve ser tomado como mera abstração ou princípio sobre o qual, à maneira cartesiana, poderíamos dedutivamente erigir uma teoria. Ele deve ser pensado antes como uma aparição fundamental (Grunderscheinung) no interior da qual a totalidade viva da natureza se oferece e pode servir às diversas formas de expressão humana: "olhar, saber, supor, crer e todas as antenas com as quais o homem tateia o mundo devem então agir conjuntamente quando nossa importante, embora difícil, tarefa for cumprida" (Goethe apud Heisenberg, 1971, p. 254). A unidade viva da natureza deveria ser expressa na unidade do saber humano. Logo, a abstração é válida somente quando serve a alguns resultados práticos, ou seja, quando permite não apenas o conhecimento teórico da natureza, como também sua fruição estética e seu uso moral. A teoria das cores de Goethe deveria servir aos físicos, filósofos, médicos e, sobretudo, aos artistas. Não por acaso, a última parte de sua doutrina diz respeito aos efeitos morais e sensíveis das cores. Daí a crítica de Goethe a uma ciência cujo grau de abstração ultrapassa nossa intuição viva do mundo e que isola a verdade da moral e da estética. Como bem observa Heisenberg:

Para Goethe, a verdade era inseparável do conceito de valor. O "unum, bonum, verum", o "uno, bom, verdadeiro", era para ele, assim como para os antigos filósofos, o único compasso pelo qual a humanidade poderia se orientar através dos séculos na busca de seu caminho. Uma ciência que é apenas exata (richtig), na qual os conceitos de "exatidão" e "verdade" encontram-se separados, na qual a ordem divina já não norteia a partir de si mesma, é por demais arriscada e deve ser, pensando novamente no Fausto de Goethe, rejeitada como obra do demônio (1971, p. 252). 


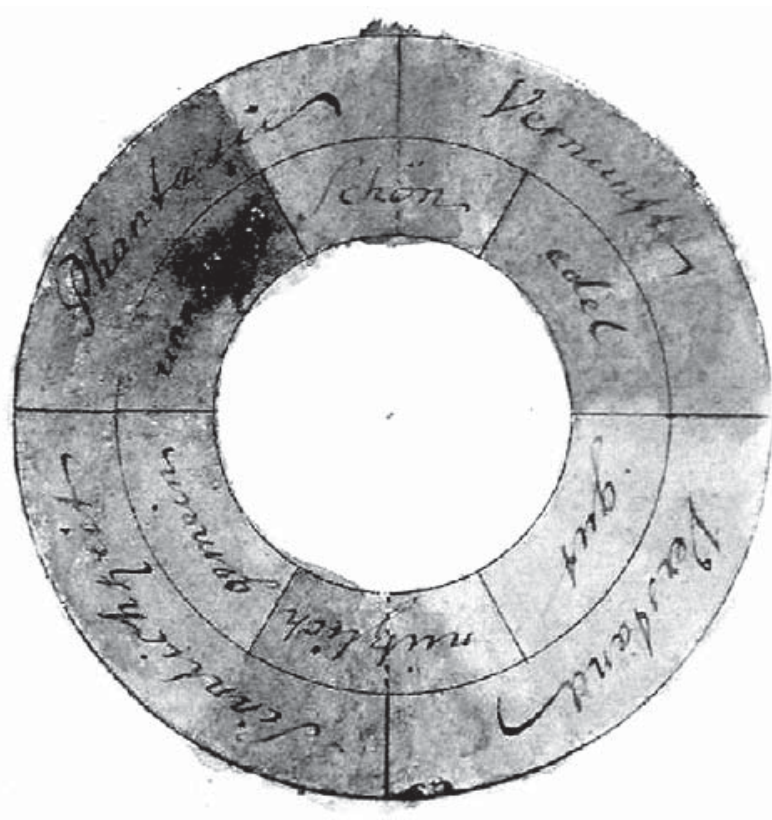

Figura 3. O círculo das cores desenhado por Goethe, extraído do capítulo acerca da ação ético-moral das cores. No círculo interior, cada cor é relacionada a um adjetivo estético-moral: o vermelho ao belo (schön); o laranja ao nobre (edel); o amarelo ao bom (gut); o verde ao útil (nützlich); o azul ao vulgar (gemein) e o roxo ao desnecessário (unnöthig). No círculo exterior, as interseç̧ões das cores correspondem às faculdades da alma: vermelho/laranja razão (Vernunft); amarelo/verde - entendimento (Verstand); verde/azul-sensibilidade (Sinnlichkeit) e roxo/vermelho-fantasia (Phantasie).

Devemos cuidar aqui para não pensarmos que Goethe tem como ideal uma natureza humanizada. Não apenas a ciência moderna mas também o romantismo é alvo de suas críticas. Os românticos também desprezariam a unidade da natureza, tornando-a prisioneira da subjetividade humana. Como observa Heisenberg:

Toda arte que, assim como o romantismo, distancia-se do mundo, que já não corresponde ao mundo efetivo, mas apenas ao seu espelhamento na alma do artista, parece a ele [Goethe] tão insatisfatória quanto uma ciência que não toma como objeto a natureza livre, e sim fenômenos isolados, selecionados e, em certa medida, preparados através de aparelhos" (1971, p. 255).

A "natureza livre" é, para Goethe, aquela que intuímos diretamente através dos sentidos. Ao investigador da natureza cabe escutar a linguagem pela qual ela fala à nossa intuição e reconhecer os nexos de sua ordenação viva. A intenção principal de sua doutrina das cores "era aplicar essa designação universal, essa linguagem natural, também à teoria das cores, enriquecer e ampliar essa linguagem mediante a teoria das cores e, assim, facilitar o compartilhamento das mais elevadas intuições (Anschaungen) entre os amigos da natureza" (Goethe, 2010, loc. 1066). Ao se afastarem dos sentidos, em direção a abstrações matemáticas ou aos estados da alma, tanto o físico como o romântico teriam fechado os ouvidos à linguagem da natureza e desprezado o valor da sua unidade e ordenação internas. 
Segundo Heisenberg, Goethe não está totalmente errado. Para ele, todo aumento de nosso conhecimento sobre a natureza implica uma limitação e uma renúncia na compreensão do mundo em sua totalidade. Todo avanço na ciência implica o sacrifício de alguns questionamentos e construções conceituais anteriormente conquistados:

a observação da natureza pelo homem remete aqui a uma analogia com o ato isolado da percepção que podemos conceber, como o faz Fichte, como uma "autolimitação do Eu": em cada ato perceptivo nós escolhemos uma determinada possibilidade em meio a uma abundância ilimitada e, assim, limitamos a plenitude de possibilidades para o futuro (Heisenberg, 2005b, p. 2).

Desse modo, não podemos dizer que a doutrina das cores de Newton é mais ou menos verdadeira que a de Goethe, pois ambas as teorias tratam de níveis diferentes da realidade: o poeta fala a partir da natureza viva que se comunica através dos nossos sentidos e o cientista a partir de uma natureza matematicamente quantificada e experimentalmente forjada.

Ao analisar a disputa entre Goethe e Newton em termos de domínios da realidade, Heisenberg também desqualifica as críticas dos físicos arianos, para os quais existe apenas um domínio da realidade, qual seja, a realidade empírica acessível à intuição. Do mesmo modo que Goethe e Newton são ambos verdadeiros dentro de seus respectivos domínios, assim também a física newtoniana é verdadeira e exata na escala intuitiva da nossa experiência ordinária, ao passo que a física quântica possui o grau de exatidão exigido para fenômenos onde o quantum de ação não pode ser negligenciado. Mais ainda, para Heisenberg, aquele que não estiver preparado para renunciar a "uma ocupação viva com a natureza" e galgar os

Figura 4. Retrato de Newton em 1702, com 61 anos de idade, pintado por Godfrey Kneller.

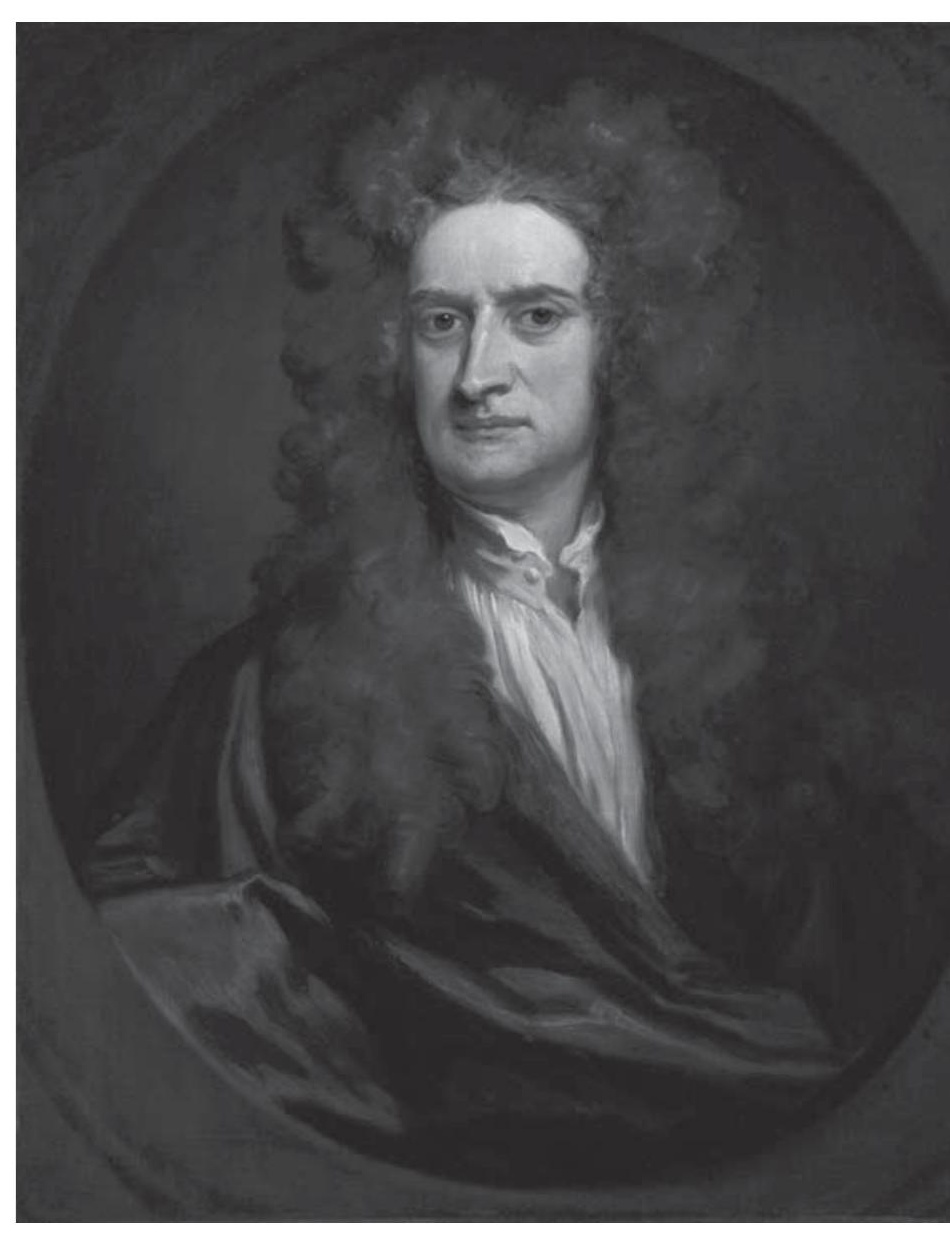


domínios abstratos da física moderna deve abandonar, ao menos por enquanto, o caminho das ciências exatas.

Entretanto, Heisenberg não descarta a possibilidade de a moderna física, com seu formalismo matemático e experimentos técnicos, poder um dia servir a uma compreensão mais viva do mundo. O físico chega mesmo a questionar se os elementos essenciais, que nos permitem estabelecer as grandes conexões na natureza, não se expressariam antes nas abstrações que se furtam à nossa intuição imediata:

mas devemos perguntar então de onde sabemos, ou de onde sabe Goethe, que as conexões mais próprias e profundas possam ser tão imediatamente visíveis, que elas se mostrem tão abertamente à luz do dia? Não poderia ser que exatamente aquilo que Goethe sente como a ordenação divina da manifestação da natureza apenas se apresente a nós, em sua plena clareza, nas abstrações mais elevadas? Não poderia a moderna ciência da natureza dar respostas que possam resistir a todas as exigência valorativas de Goethe? (Heisenberg, 1971, p. 255).

Heisenberg compara o crescente formalismo pelo qual a física moderna traduz a natureza com a ascensão ao cimo de uma montanha. Assim como um montanhista, que após atravessar regiões inóspitas onde a vida se torna escassa e o ar rarefeito, pode vislumbrar a amplitude dos vales e das paisagens abaixo de si, também o cientista poderia ter a esperança de observar, do alto de suas idealizações, a unidade viva e coesa do mundo.

Como não sabemos a qual distância estamos do cume, ou se ao menos existe um cume, a discussão entre Goethe e Newton se torna tão mais atual quanto mais abstrato nosso saber científico e maior nossa dominação técnica da natureza.@

\section{Alexandre de Oliveira Ferreira \\ Departamento de Filosofia, Universidade Federal de São Paulo, Brasil. deoferreira@hotmail.com}

\section{Heisenberg and the doctrine of colors of Goethe and Newton}

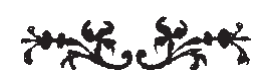


This paper aims at exposing the Heisenberg's conference "The teachings of Goethe and Newton on colors in the light of modern physics", presented in 1941, whose translation is presented here. In the first place the paper analyzes the philosophical project of an ordination of the reality, developed by the physicist in the early 1940 and which is the basis for the discussion of the "Teachings of Goethe and Newton on colors". Secondly it exposes some philosophical implications of the quantum theory by emphasizing the point of view of the Copenhagen school. Finally, it shows how the dispute between Goethe and Newton is exploited to defend the abstractions of the theoretical physics against the attacks of the so called "German physicists" and, at the same time, to preserve the worth of the Goethe's intuitive analysis.

\section{REFERÊNGIAS BIBLIOGRÁFIGAS}

BeZERRA, V. A. Schola quantorum: progresso, racionalidade e inconsistência na antiga teoria atômica Parte I: desenvolvimento histórico, 1913-1925. Scientix Studia, 1, 4, p. 463-517, 2003.

. Schola quantorum: progresso, racionalidade e inconsistência na antiga teoria atômica Parte II: crítica à leitura lakatosiana. Scientiæ Studia, 2, 2, p. 207-37, 2004.

Blum, W.; Dürr, H. P. \& Rechenberg, H. (Ed.). Gesammelte werke Heisenberg. München: Piper, 1984. v. 1.

__.;____. Gesammelte werke Heisenberg. München: Piper, 1985. v. 3.

. \& __. Gesammelte werke Heisenberg. München: Piper, 1986. v. 3-4.

Вонг, N. Essays 1958-1962. Atomic physics and human knowledge. New York: Wiley, 1963.

Costa, F. A. da \& Videira, A. A. P. Heisenberg contra Lenard e Stark: o que há de importante na física ariana? Revista Portuguesa de Filosofia, 63, 1-3, p. 309-50, 2007.

Einstein, A. Notas autobiográficas. Rio de Janeiro: Nova Fronteira, 1982.

Freire Júnior, O. et al. (Org.). Teoria quântica: estudos históricos e implicações culturais. Campina Grande: EDUEPB, 2009.

Gовтне, J. W. Fausto. Tradução J. K. Segall, São Paulo: Edusp, 1981. Schriften zur Naturwissenschaft. Stuttgart: Reclam, 2009.

. Zur Farbenlehre. Alternmuester: Jazzybee, 2010. (Kommentierte Gold Collectiom).

Heisenberg, W. Über den anschaulichen Inhalt der quantentheoretischen Kinematik und Mechanik.

Zeitschrift für Physik, 4,3, 3-4, p. 172-98, 1927.

. The physical principles of quantum theory. New York: Dover, 1949.

. Schritte über Grenzen: Gesammelte Reden und Aufsätze. München: Piper. 1971.

. Wandlungen in den Grundlagen der Naturwissenschaft. Stuttgart: Hirzerl, 2005.

. Der Teil und das Ganze. München: Piper, 2005a.

Die Goethe'sche und die Newton'sche Farbenlehre in Lichte der modernen Physik. In:

Wandlungen in den Grundlagen der Naturwissenschaft. Stuttgart: Hirzerl, 2005b. p. 69-88.

_. Quantentheorie und Philosophie. Stuttgart: Reclam, 2006.

_. Ordenação da realidade. Rio de Janeiro: Forense, 2009 [1942].

Hilgevoord, J. \& Uffink, J. The uncertainty principle. In: Zalta, N. (Ed.). The Stanford encyclopedia of philosophy. Summer, 2012. Disponível em: <http://plato.stan ford.edu/archives/sum2012/entries/qtuncertainty/>. Acesso em: 14, abr. 2013. 
JAMmER, M. The philosophy of quantum mechanics: the interpretations of QM in historical perspective. New Jersey: John Wiley and Sons, 1974.

Leite, A. \& SAmuel, S. Werner Heisenberg e a interpretação de Copenhague: a filosofia platônica e a consolidação da teoria quântica. Scientix Studia, 8, 2, p. 213-41, 2010.

Lenard, P. Deutsche Physik in vier Bänden. München: Lehmanns, 1936. v. 1.

Menra, J. Niels Bohr's discussions with Albert Einstein, Werner Heisenberg, and Erwin Schrödinger: The origins of the principles of uncertainty and complementarity. Foundations of Physics, 17, 5, p. 461-506, 1987 .

Paty, M. A matéria roubada. São Paulo: Edusp, 1995.

Rozema, L. A. et al. Violation of Heisenberg's measurement: disturbance relationship by weak measurements. Physical Review Letters, 109, p. 1-5, 2012.

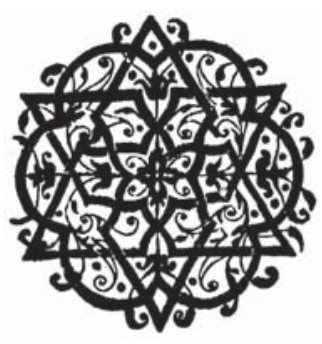

